\title{
Estudio Exploratorio II. Identificación de Nanopartículas en Procesos Industriales de Soldadura y de Minería
}

\section{EXPLORATORY STUDY II IDENTIFICATION OF NANOPARTICLES IN INDUSTRIAL PROCESSES WELDING AND MINING}

\author{
Ximena Blamey Benavides ${ }^{1}$, Edgar Mosquera ${ }^{2}$, Francisco Díaz ${ }^{3}$ \\ 1. Experto Profesional en Prevención de Riesgos, Consultor en Sistemas de Gestión, Santiago, Chile. \\ 2. Departamento de Ciencia de los Materiales, Universidad de Chile, Beauchef 851 Sur-Poniente, piso 4-5, Santiago, Chile. \\ 3. Consultor en Seguridad y Salud Ocupacional, Santiago, Chile.
}

\begin{abstract}
RESUMEN
Se realizó un estudio exploratorio sobre la exposición laboral a nanopartículas en procesos de empresas del sector minero, fundición y soldadura.

Para evaluar la exposición se utilizó un método cualitativo simplificado y un método semi-cuantitativo basado en las técnicas tradicionales de higiene ocupacional y de espectroscopía y microscopía electrónica para caracterizar las nanopartículas en cuanto a composición elemental, morfología y tamaños.

Se evaluó cualitativamente el riesgo de exposición a nanopartículas de sílice y hierro, encontrándose una mayor criticidad en los procesos de preparación de muestras de minerales y de vaciado de colada en moldes de fundición.

El análisis de muestras personales y ambientales evidenció la exposición de trabajadores a nanopartículas de sílice, hierro, magnesio, aluminio, manganeso, entre otras. La toxicidad de estas depende de la morfología y vía de ingreso (la principal vía es por inhalación). Se identificaron morfologías esféricas e irregulares, así como nanoalambres, aglomerados, estructuras cristalinas y amorfas, con tamaños bajo $100 \mathrm{~nm}$.

El trabajo realizado entrega la composición elemental y morfológica de las nanopartículas a los cuales se exponen los trabajadores en los procesos evaluados, junto con el alcance de los métodos de evaluación y la necesidad futura de realizar estudios cuantitativos para determinar niveles de exposición y concentraciones.
\end{abstract}

(Blamey X, Mosquera E, Díaz F, 2016. Estudio Exploratorio IL. Identificación de Nanopartículas en Procesos Industriales de Soldadura y de Minería. Cienc Trab. Ene-Abr; 18 [55]: 28-36).

Palabras clave: NANOTECNOLOGIA, NANOPARTICULAS, NANOMATERIALES, HIGIENE INDUSTRIAL, EVALUACIÓN SEMI-CUANTITATIVA, TOXICIDAD.

\section{ABSTRACT}

An exploratory study on occupational exposure to nanoparticles in processes of mining companies, casting and welding was performed. To assess exposure it was used a simplified qualitative and semiquantitative method based on traditional techniques of occupational hygiene and spectroscopy and electron microscopy to characterize nanoparticles in terms of elemental composition, morphology and size.

The risk of exposure to silica nanoparticles and iron was qualitatively assessed, finding a bigger criticality in the process of sample preparation and emptying mineral casting molds.

Analysis of personal and environmental samples showed workers exposure to nanoparticles of silica, iron, magnesium, aluminum, manganese, among others. The toxicity of these depends on the morphology and route of entry (the main way is by inhalation). Spherical and irregular morphologies were identified, as well as nanowires, crystalline and amorphous structures with sizes below $100 \mathrm{~nm}$.

The work performed gives the elemental composition and morphology of nanoparticles to which workers are exposed in the processes evaluated, along with the scope of the evaluation methods and the future need for quantitative studies to determine exposure levels and concentrations.

Key words: NANOTECHNOLOGY, NANOPARTICLES, NANOMATERIALS, INDUSTRIAL HYGIENE, EVALUATION SEMIQUANTITATIVE, TOXICITY.

\section{INTRODUCCIÓN}

Recientes estudios estiman que para el año 2020 aproximadamente 10.000.000 de trabajadores estarán expuestos a nanomateriales en industrias de nanotecnología, cifra que no incluye a los

Correspondencia / Correspondence:

Ximena Blamey Benavides

e-mail: ximena.blamey@gmail.com

Recibido: 01 de Agosto de 2015 / Aceptado: 09 de Diciembre de 2015 trabajadores que se exponen a nanopartículas que se generan en sus procesos y que contaminan los ambientes laborales. El estado del arte muestra que aún existen brechas en el conocimiento del efecto de las nanopartículas sobre el organismo del ser humano, toxicología, exposición y caracterización de las nanopartículas presentes en distintos ambientes laborales, así como en el equipamiento para una evaluación consistente del riesgo higiénico y en los métodos de análisis para cuantificar las nanopartículas. La preocupación por los posibles efectos adversos para la salud por el contacto con los nanomateriales se ha elevado en los últimos 10 años, debido a que diferentes estudios toxicológicos in vitro e in vivo en animales y cultivos celulares ${ }^{1-3}$ han mostrado que los nanomateriales presentan, a esa escala, propiedades bioló- 
gicas nuevas tales como la translocación hacia órganos secundarios, inadecuada eliminación por parte de los macrófagos, capacidad de ser transportados a través de los axones de las neuronas sensoriales y, además, que pueden acceder a las estructuras intracelulares tales como las mitocondrias y núcleos. Estas propiedades, que no son apreciables en estos materiales cuando se encuentran en bloque (tamaño del orden de micras), pueden causar daños adicionales o pueden inducir nuevos efectos adversos para la salud. Por lo tanto, es posible que la introducción de nanomateriales o la generación por defecto en los procesos en ambientes de trabajo pueda provocar efectos imprevisibles y graves para los trabajadores expuestos a estos materiales.

Un equipo de investigadores realizó una intensa búsqueda de publicaciones asociados al daño que produce la exposición a nanopartículas; solo 11 artículos científicos calificaron como tales. De estos solo 4 establecian relaciones entre exposición, efecto tóxico en el organismo y daño posterior a la exposición a nanopartículas. Tres de cuatro casos mencionaban toxicidad respiratoria, evidenciaban la relación de exposición a altas concentraciones con la presencia de nanopartículas en órganos diana (se encontró dióxido de titanio en tejidos pulmonares, nanotubos de carbón en tejidos pulmonares en 3 de 4 trabajadores expuestos a polvo del derrumbe de las Torres Gemelas, macrófagos pulmonares con partículas de níquel de $25 \mathrm{~nm}$ en un trabajador que realizaba un proceso de niquelado por arco eléctrico) y 2 casos sobre toxicidad dermatológica. Si bien es cierto expone la severidad del daño producto de altas concentraciones, también alude a la ausencia de ventilación y protección personal. La búsqueda fue exhaustiva, encontrando solo estos casos aislados en relación al gran auge de la industria de la nanotecnología y concluye que aún existen muy pocos estudios sobre la toxicología de las nanopartículas y conocimiento de las exposiciones a partículas de tamaños a nanoescala. ${ }^{4}$

Otros antecedentes sobre la toxicidad de las nanopartículas aluden a su toxicidad intrínseca. Esta depende de factores físicos y químicos; se debe considerar que:

- A medida que disminuye el tamaño de la partícula, el área superficial por unidad de masa aumenta, lo que conlleva un mayor número de átomos en la superficie. Cuanto mayor sea esta, mayor será la reactividad y más tóxica la partícula.

- Las nanopartículas tienen tendencia natural a unirse formando agregados y aglomerados, modificándose así no sólo el lugar en el que se depositan sino también su toxicidad.

- Un mismo material se comporta de forma distinta si se halla en macro o en la nanoescala.

La tóxico-cinética de las nanopartículas se muestra en forma general de acuerdo a las vías de ingreso (piel, inhalación, ingestión, inyección), las que se distribuyen y pueden sufrir una translocación, y según el grado de solubilidad pueden ser eliminadas vía sudor o exfoliación, orina, leche materna o heces. ${ }^{5.6}$

En el primer estudio financiado por FUCYT (2011-2012) sobre nanopartículas, "Estudio exploratorio de higiene industrial y seguridad básica en unidades de trabajo que generan o manipulan nanopartículas, o que emplean nanotecnología en sus procesos"7, solo permitió concluir sobre la presencia de estas partículas y no permitió ser concluyente sobre exposiciones laborales, dado el bajo número de muestras utilizadas en el estudio y el método de análisis que se estaba probando.

El presente trabajo tiene como objetivo explorar la exposición laboral a nanopartículas en procesos soldadura, fusión de metales en procesos industriales de fundición y minería.

\section{METOdOLOGÍA}

Dado que la Nanotecnología en nuestro país se encuentra en una etapa de desarrollo, esta investigación tiene un carácter de tipo exploratorio no probabilístico y se realiza de acuerdo con las siguientes etapas:

- Revisión bibliográfica del estado del conocimiento respecto de los riesgos para la salud.

- Se realizó la toma de muestras ambientales y personales en procesos de: minería, fundición y soldadura.

- Evaluación semicuantitativa de la exposición ambiental utilizando los métodos convencionales para la toma de muestras en filtros de PVC y éster de Celulosa de $37 \mathrm{~mm}$, conectados a bombas portátiles Gilian Modelo Gil Air 3, empleando ciclones solo en operaciones de minería.

- La composición y morfología de las nanopartículas se realizó mediante el análisis con técnicas de espectroscopía FRX, microscopía electrónica SEM y TEM, y energía dispersiva de rayos X (EDX). Debido a la extensión del trabajo solo se presentan las imágenes obtenidas por microscopía TEM.

\section{RESULTADOS}

\section{Evaluaciones semicuantitativas}

A continuación se presentan los principales procesos y resultados de las evaluaciones realizadas por microscopía electrónica TEM.

- Proceso Minería-Muestrera y Molino

Descripción del proceso en la Muestrera: Se muestreó el proceso que se realiza en la muestrera, el que consideró las etapas de homogenizado, cuarteo y pulverizado de muestras de mineral con contenido de oro y plata; la sala, habilitada con sistemas de extracción forzada.

Se tomó una muestra personal, instalando el filtro a la altura de las vías respiratorias del operador de cuarteo, y una muestra ambiental, en las cercanías del sector de bandejas con muestras de polvos.

Resultados del análisis por microscopia TEM: Se encontró que las muestras presentan una morfología irregular (submicroparticulas $<1 \mu \mathrm{m}$ ), además de nanopartículas con diámetro menores a los 100 nm, según se observa en la Figura 1 y Figura 2.

\section{Figura 1.}

Imágenes TEM de partículas obtenidas en el filtro 83 (ambiental).

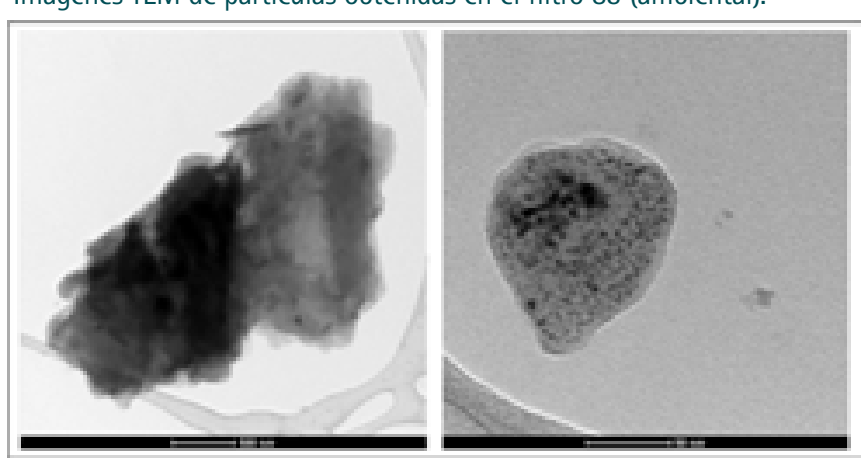


Figura 2.

Imágenes TEM de partículas obtenidas en el filtro 84 (personal).
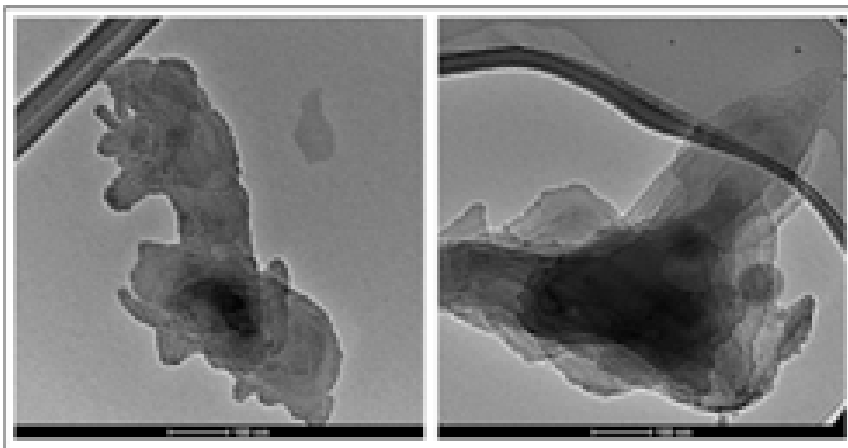

Figura 3.

Imagen TEM (izq.) y el patrón de difracción de electrones de la imagen, evidencia estructuras cristalinas. (Abajo) Análisis composicional EDS de las submicropartículas.

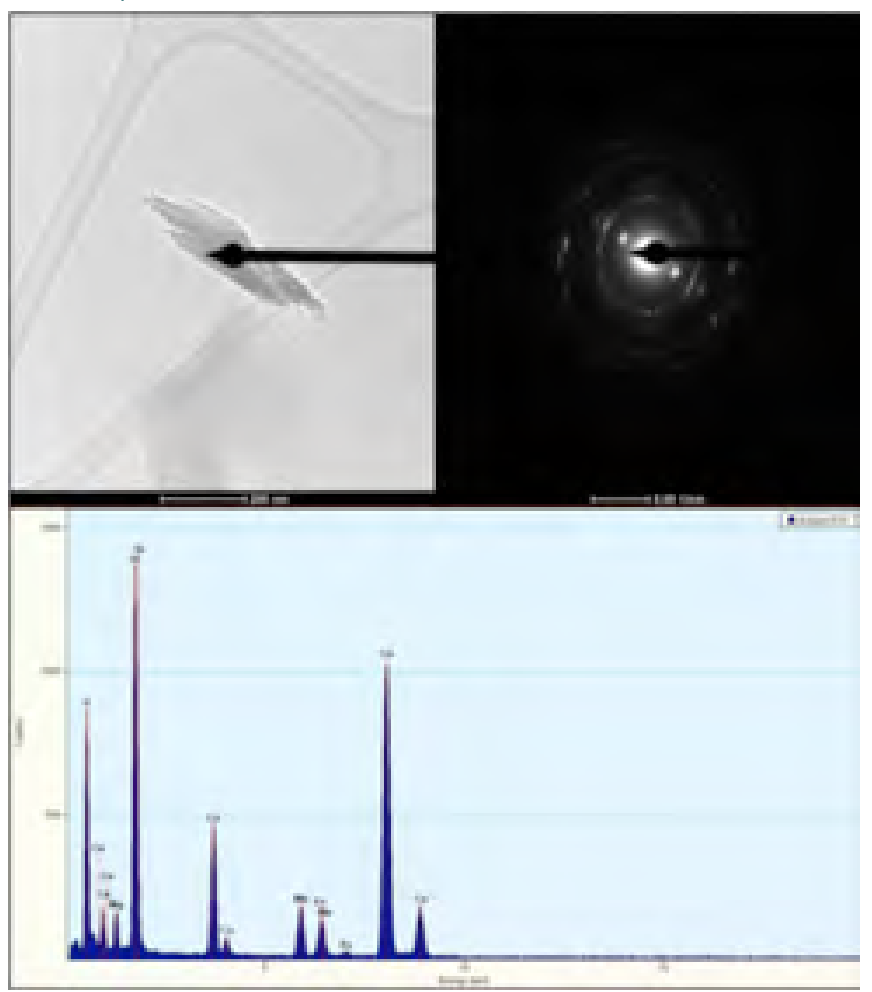

Tabla 1.

Cuantificación elemental de la Figura 19. (Filtro 84, personal).

\begin{tabular}{|ccc|}
\hline Elemento & $\%$ peso & \% atómico \\
\hline $\mathrm{O}(\mathrm{K})$ & 32,49 & 50,69 \\
$\mathrm{Si}(\mathrm{K})$ & 33,33 & 29,62 \\
$\mathrm{Fe}$ & 6,80 & 3,04 \\
$\mathrm{Mn}$ & 8,75 & 3,97 \\
$\mathrm{Mg}$ & 2,64 & 2,71 \\
$\mathrm{Ca}$ & 15,96 & 9,94 \\
\hline
\end{tabular}

La Figura 3 muestra el análisis composicional (EDS) y el patrón de difracción de electrones de área seleccionada (parte inferior) tomado a las nanopartículas recolectadas en el Filtro 84; mostró que las partículas están conformadas por $\mathrm{O}(\mathrm{K}), \mathrm{Si}(\mathrm{K}), \mathrm{Fe}(\mathrm{K}), \mathrm{Mn}, \mathrm{Mg}$, Ca. La Tabla 1 muestra una cuantificación de los resultados de EDS obtenidos de las partículas de la Figura 3.
El patrón de difracción nos muestra que las partículas son policristalinas, teniendo en consideración que el patrón ha sido tomado al conjunto de partículas de la imagen de la Figura 3 (lado derecho superior).

Los resultados de los procesos muestreados permiten concluir que: - Los principales agentes higiénicos son la Sílice, Níquel, Cinc, Calcio, Hierro y Manganeso.

- Se comprobó la existencia de estructuras policristalinas, con nanopartículas con composición elemental conformadas por 0 $(\mathrm{K}), \mathrm{Mg}(\mathrm{K}), \mathrm{Al}(\mathrm{K}), \mathrm{Si}(\mathrm{K}), \mathrm{S}(\mathrm{K}), \mathrm{K}(\mathrm{K})$, Ca (K).

- El polvo colectado contiene partículas a escala nanométrica, < $100 \mathrm{~nm}$, encontrándose hasta bajo $20 \mathrm{~nm}$.

- Estos resultados refuerzan el hecho de que en procesos mineros se produce exposición de los trabajadores a nanopartículas con estructuras cristalinas (patrón de difracción de electrones), lo cual incrementa el riesgo. Los patrones de TEM muestran silicio y/o aluminosilicatos, presentando estructuras cristalinas de tamaños de $10 \mathrm{~nm}$ aproximadamente.

\section{- Proceso Soldadura MIG-Puesto Soldadura estructura en cabina de soldadura}

Descripción del proceso de recolección de muestras: se evalúa la exposición a humos en tarea de soldadura MIG de una estructura de acero básico A-36, ubicada al interior de un galpón con ventilación natural, existiendo cabinas para cada operador de soldadura. Cada cabina es, aproximadamente, de 3,5 m de ancho y $5 \mathrm{~m}$ de fondo, cuenta con separaciones de paneles metálicos hasta una altura aproximada de 2 metros, cuenta con extracción localizada (campana de extracción móvil, con brazo extensible de acuerdo a la necesidad del soldador) y biombos, que separan el espacio asignado para la operación del pasillo central demarcado que comunica las cabinas en la nave. Durante el muestreo no se encontraba en buen estado la extracción localizada (retraso en mantención); se asignó esta cabina por encontrarse en la situación más desfavorable higiénicamente. El soldador soldó un marco de transferencia para cátodos de cobre; la operación duró 14 minutos. En el lapso de tiempo muestreado el operador alcanzó a aplicar un cordón 2 $\mathrm{m}$ de soldadura con $6 \mathrm{~mm}$ de ancho.

El electrodo utilizado es de Indura, código ER 70S-6 de 1,2 mm; se usó mezcla de gas Indurmig 20, trabajo a 120 amperes. La composición del electrodo es: C 0,08\%; Mn 1,44\%; Si 0,86\%; P 0,012\%; S 0,014\%; Cr 0,02\%; Ni 0,04\%; Mo 0,003\% V 0,005\%; Cu 0,20\%; siendo los elementos de mayor importancia para el proceso el Silicio y Manganeso por sus propiedades desoxidantes.

Se tomaron muestras del humo emitido durante una tarea de soldadura que consumió parte de un carrete de electrodo ER 70S-6, utilizando filtros de celulosa de $37 \mathrm{~mm}$ conectados a bombas portátiles Gilian Modelo Gil Air 3. Estas incluyeron una muestra personal, instalando el filtro a la altura de las vías respiratorias del soldador, y una muestra ambiental en la cabina en la cercanía del sector de soldadura de la estructura, para posteriormente llevarlas a análisis mediante microscopía electrónica.

- Resultados del análisis por microscopía TEM: Al realizar el estudio mediante microscopía de transmisión (TEM) encontramos que las muestras presentan una morfología esférica y de tamaño nanométrico (menores de $100 \mathrm{~nm}$ ), lo cual implicaría que son producidas por el arco de la soldadura (antropogénicos), según se observa en la Figura 4.

$\mathrm{Al}$ analizar las nanopartículas, presentan una concentración elemental de 0 (72 \%p), Si (6 \%p), Mn (1,79 \%p), y Fe (17,72 \%p). Esta compo- 


\section{Figura 4.}

Imágenes TEM de nanopartículas obtenidas en el filtro CFM-699 (arriba) y análisis elemental EDS (abajo). El patrón de difracción de electrones muestra la presencia de estructuras cristalinas (puntos brillantes) y amorfa; esto se aprecia en la parte inferior derecha de la figura.

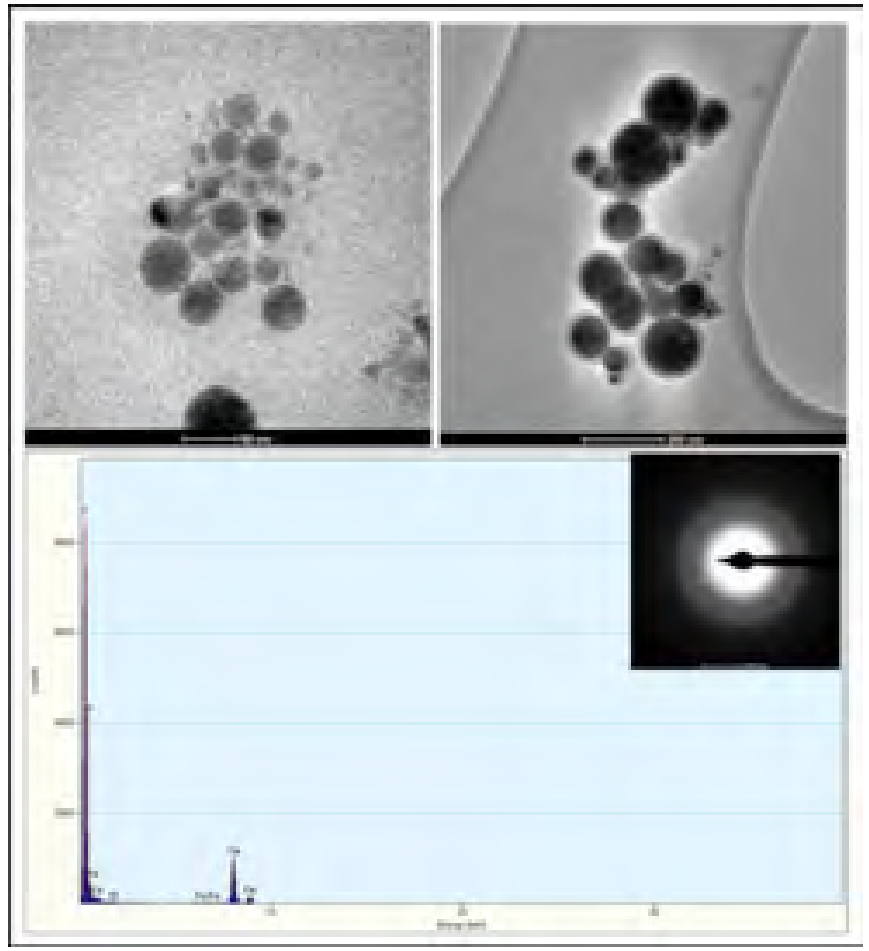

sición proviene de la soldadura. La composición de estas nanopartículas esféricas (Figura 4) contrasta muy bien con la composición del electrodo de soldadura y además con las mediciones realizadas mediante análisis FRX y SEM/EDS de los filtros CFM 699 (personal). Es de notar que gran parte del carbono es proveniente del soporte y el cobre de la rejilla; por ende, no consideramos su porcentaje en peso. Es importante destacar que al realizar el análisis de difracción de electrones aparecen estructuras cristalinas y amorfas. En este caso no podemos discriminar directamente del patrón de difracción si la sílice (6\%) es cristalina ya que hay presencia de Fe $(17,72 \%)$. Un estudio más profundo es requerido para determinar la cristalinidad de la sílice.

Para el filtro CFM700 (ambiental), ver Figura 5; encontramos nanopartículas esféricas con composición y tamaños similares al filtro CFM699. Además, de submicropartículas granulares no esféricas con composición elemental de 0 (9,92\%p), Na (31,74\%p), Si (0,59\%p), $\mathrm{S}(0,31 \%$ ), K (1,42 \%p), Fe (0,77 \%p) y Zn (6,68\%p). El C y el Cu son provenientes en su mayoria de la rejilla de transmisión.

De los resultados de los procesos de soldadura MIG muestreados se concluye que:

- Los principales agentes de riesgo higiénico encontrados son el Fierro, Manganeso y Sílice.

- En el caso del Manganeso, sólo se detectó en la muestra personal en un \% peso bajo en comparación al Fierro y Sílice.

- La principal morfología de las nanopartícula es de carácter esférica de tamaños $<100 \mathrm{~nm}$, y presentan aglomerados irregulares, donde podrian encontrarse algunas estructuras cristalinas con morfología regular (hexagonales) y de tamaño inferior a $20 \mathrm{~nm}$.

- El Aluminio encontrado en las muestras a escala micro- y
Figura 5.

Imágenes TEM de nanopartículas obtenidas en el filtro CFM-700 ambiental (arriba) y análisis elemental EDS (abajo).

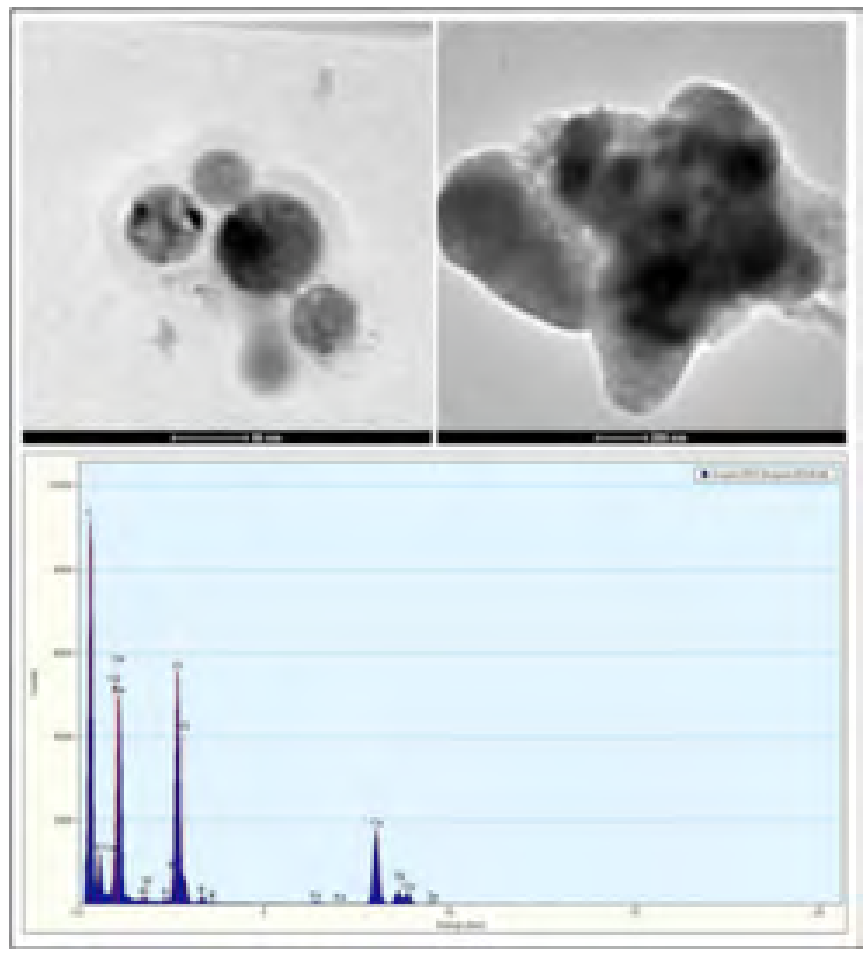

submicrométrica no se encuentra a escala nano; posiblemente el Aluminio es un elemento residual en el ambiente producto de otros procesos de soldadura. Esta situación se observó en ambas empresas, en las cuales se realizó soldadura.

- En una de las muestras ambientales se encontró un alto \% peso de Sodio (Na); posiblemente este elemento está como residente en el ambiente y puede provenir de procesos de limpieza de estructuras o del metal a soldar, lo que no es posible concluir con la información disponible.

- En relación al primer estudio de nanopartículas donde se encontró sílice en estado amorfo, en el presente estudio además se corrobora la presencia de nanopartículas de sílice posiblemente en estado cristalino, lo cual debe generar una alerta en las evaluaciones tradicionales de higiene industrial, incluyendo este agente en ambos estados como parte de los análisis, dado que a nivel de nanopartículas amorfas se desconoce su efecto sobre el organismo y no hay mayores estudios.

- La discusión existente sobre el carácter cancerígeno de la sílice a tamaño nanoescala quedará para estudios posteriores, si estudios epidemiológicos lo evidencian.

- Proceso de fundición-vaciado de material fundido.

Descripción del proceso recolección de muestras: Se muestreó el proceso de vaciado de material fundido de horno de inducción a cuchara (bajo campana de extracción, $30 \mathrm{~min}$ ) y el proceso de vaciado de material fundido a moldes (área de mecanizado, 30 min). Se fundieron $700 \mathrm{Kg}$ de material. El ciclo de la operación duró aproximadamente $1.5 \mathrm{hr}$, desde la carga, fundición, vaciado a crisoles, vaciado a moldes. En la nave existe ventilación natural, y en el sector del horno existe una chimenea de extracción de los humos de fundición. 
Se tomaron muestras del humo emitido durante una tarea de traslado y vaciado de la colada en moldes, utilizando filtros de celulosa de $37 \mathrm{~mm}$ conectados a bombas portátiles Gilian Modelo Gil Air 3. Estas incluyeron una muestra personal, instalando el filtro a la altura de las vías respiratorias del operador de vaciado de la colada en moldes, y una muestra ambiental, en las cercanías del sector de vaciado a moldes (tren mecanizado), para análisis mediante microscopía electrónica para su caracterización.

- Resultados del análisis por microscopía TEM: Al realizar el estudio mediante microscopía de transmisión (TEM) se encontró que las muestras presentan una morfología irregular (submicropartículas < $500 \mathrm{~nm}$ ), además de nanopartículas con diámetro menores a los $50 \mathrm{~nm}$; según se observa en la Figura 6 a, b y en c, se muestra la presencia de estructuras cristalinas; la composición elemental de las partículas se muestra en la Tabla 2. La composición de estas partículas es consistente con lo reportado por FRX y SEM, además de presentar una estructura cristalina.

Figura 6.
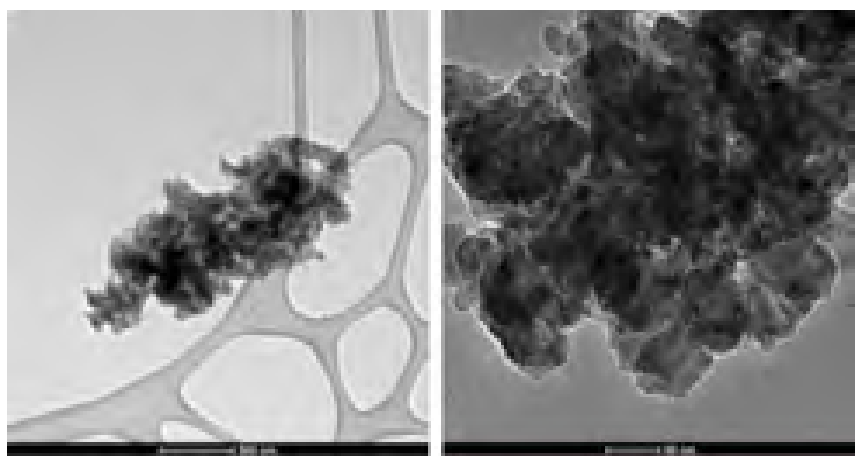

Figura 6a.

Imágenes TEM de partículas obtenidas en el filtro personal CFM-1694 (arriba) y ambiental CFM-1695 (abajo).
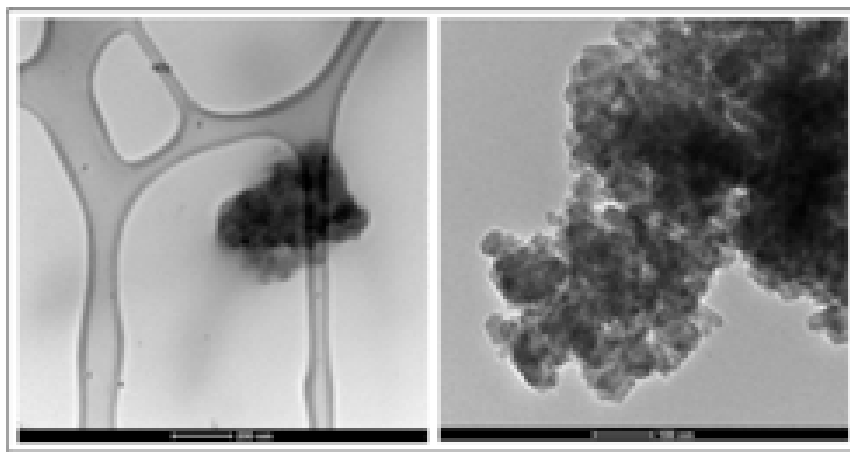

Tabla 2.

Análisis elemental de las partículas por TEM/EDS.

\begin{tabular}{|c|c|c|c|c|}
\hline \multirow[b]{2}{*}{ Elemento } & \multicolumn{2}{|c|}{1694 (nanopartículas) } & \multicolumn{2}{|c|}{1695 (nanopartículas) } \\
\hline & $\% p$ & \%а & $\% p$ & $\% a$ \\
\hline (0) & 51,58 & 65,68 & 58,56 & 71,98 \\
\hline$(\mathrm{Mg})$ & 2,29 & 1,92 & 0,78 & 0,63 \\
\hline$(\mathrm{Si})$ & 27,04 & 19,61 & 33,28 & 23,30 \\
\hline (Ca) & 0,73 & 0,37 & 1,10 & 0,54 \\
\hline (Fe) & 1,90 & 0,69 & 1,06 & 0,37 \\
\hline (S) & 0,81 & 0,51 & 2,49 & 1,53 \\
\hline (Ti) & --- & --- & 0,11 & 0,04 \\
\hline$(\mathrm{K})$ & 2,50 & 1,30 & 1,36 & 0,68 \\
\hline (Al) & 13,11 & 9,90 & 1,22 & 0,89 \\
\hline
\end{tabular}

Figura 6 b.

Imágenes EDS de partículas obtenidas en el filtro CFM-1694 (arriba) y CFM-1695 (abajo).
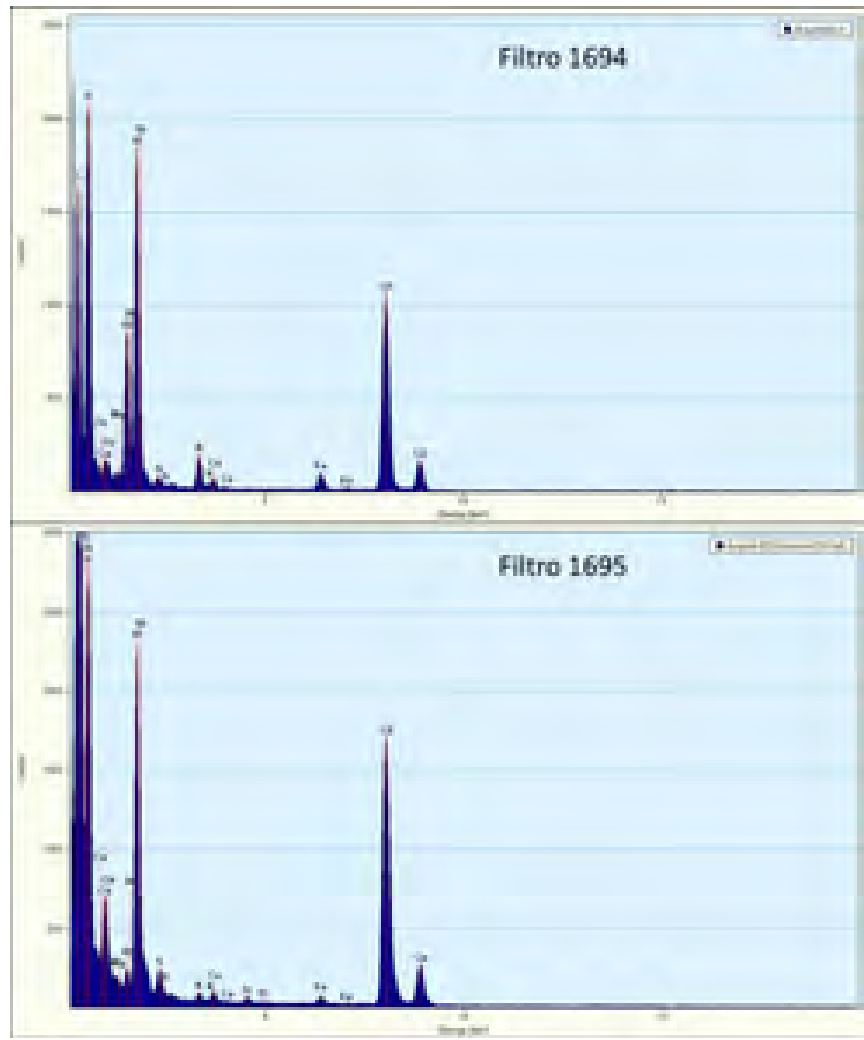

Figura 6c.

Imágenes TEM y patrón de difracción de electrones obtenido en el filtro CFM-1694 (arriba) y CFM-1695 (abajo).

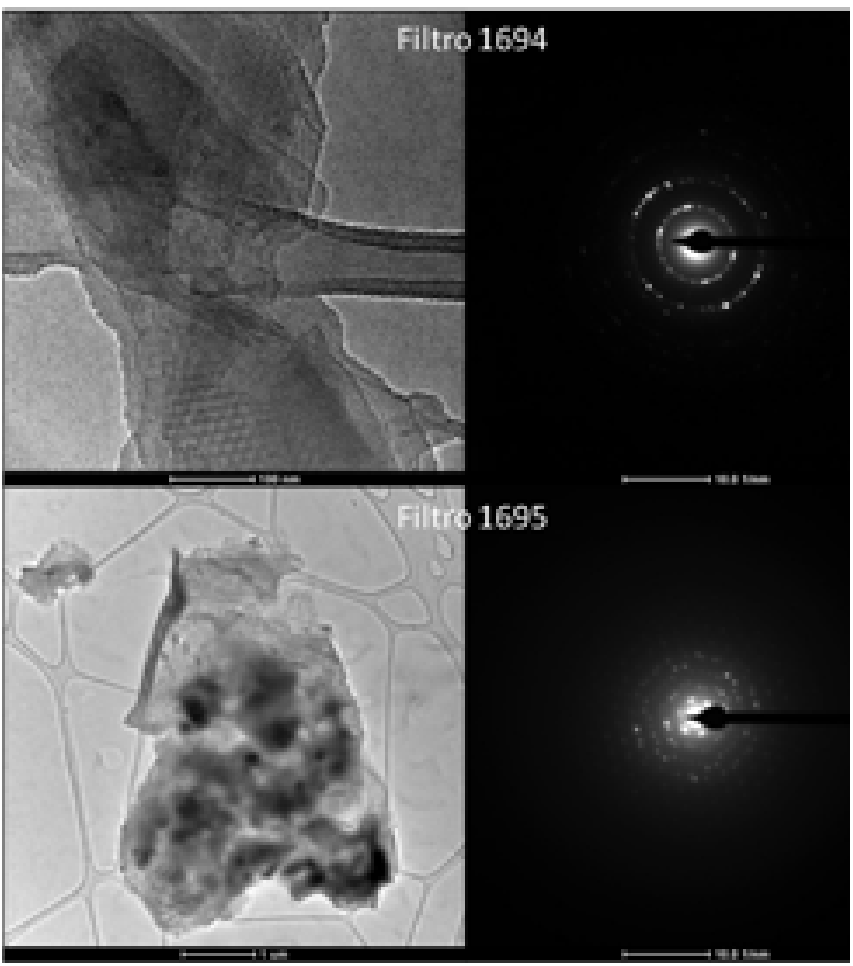


- Proceso de fundición-vaciado de metal fundido en moldes de arena.

Descripción del proceso de recolección de muestras: Se muestreó el proceso de vaciado de metal fundido de horno a capacho y de capacho a moldes de arena. La mezcla fundida en un horno de inducción de $1100 \mathrm{Kg}$ de material nodular. La composición de la mezcla fue: $800 \mathrm{Kg}$ de acero, $300 \mathrm{Kg}$ de recuperado nodular, 20 $\mathrm{Kg}$ de grafito, $17 \mathrm{Kg}$ de Fierro-Silicio, Manganeso nodulizante en proporción 3,1 Kg por $200 \mathrm{Kg}$ de fundido. Se vaciaron en moldes aprox. $1000 \mathrm{Kg}$ de mezcla fundida, en moldes que se encontraban en la Cancha de Fundición. Este material fundido se reparte en 4 cargas, 2 x $200 \mathrm{Kg}$ y 2 x $300 \mathrm{Kg}$. La operación considera el vertido en una cubeta de aproximadamente de 45 $\mathrm{Kg}$, la que es trasladada por dos operadores a la cancha donde se encuentran los moldes, posteriormente la colada es vaciada en estos. Este ciclo dura aproximadamente 45 minutos. En la nave existe ventilación natural, y en el sector del horno existe una chimenea de extracción de los humos de fundición.

La muestra ambiental (filtro 2184) se tomó en un sector entre horno más próximo al horno que a la cancha de moldes. La muestra personal (filtro 2183) se tomó al trabajador que realiza la tarea de traslado y vaciado de la colada en moldes de arena. Utilizando filtros de celulosa de $37 \mathrm{~mm}$ conectados a bombas portátiles Gilian Modelo Gil Air 3. Estas incluyeron una muestra personal, instalando el filtro a la altura de las vías respiratorias del operador de vaciado de la colada en moldes, y una muestra ambiental en las cercanías del sector de Vaciado para análisis mediante microscopía electrónica para su caracterización.

- Resultados del análisis por microscopía TEM: Al realizar el estudio mediante microscopía electrónica de transmisión (TEM) encontramos que las muestras presentan una morfología esférica

Figura 7.

Imágenes TEM y EDS de nanopartículas obtenidas en el filtro CFM-2183 (personal).

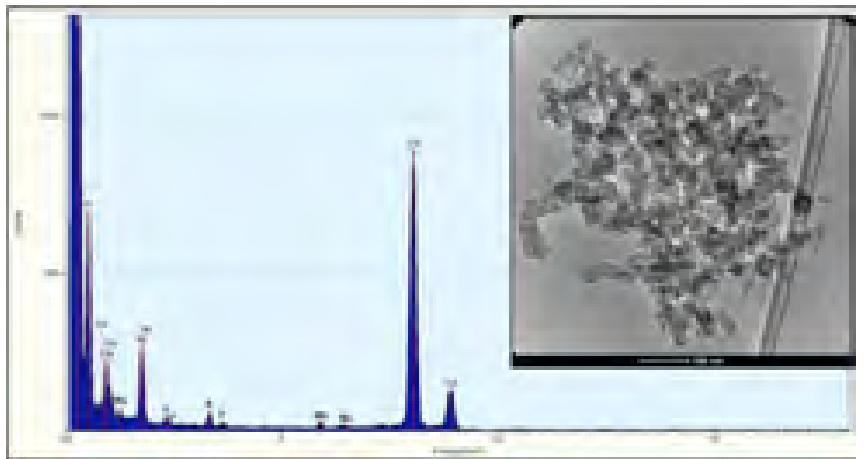

Tabla 3.

Análisis elemental de las partículas por TEM/EDS.

\begin{tabular}{lcccccc} 
& \multicolumn{2}{c}{2183} & \multicolumn{2}{c}{2184} & \multicolumn{2}{c}{2184} \\
Elemento & (nanopartículas) & \multicolumn{2}{c}{ (nanopartículas) } & \multicolumn{2}{c}{ (micropartículas) } \\
$(\mathrm{O})$ & $\% \mathrm{p}$ & $\% \mathrm{o}$ & $\% \mathrm{p}$ & $\% \mathrm{o}$ & $\%$ & $\% \mathrm{a}$ \\
$(\mathrm{Mg})$ & 73,14 & 83,91 & 39,90 & 69,36 & 36,40 & 46,67 \\
$(\mathrm{Si})$ & 1,89 & 1,43 & --- & --- & 62,61 & 52,85 \\
$(\mathrm{~K})$ & 16,72 & 10,93 & 1,45 & 1,43 & 0,28 & 0,21 \\
$(\mathrm{Fe})$ & 5,05 & 2,37 & --- & --- & --- & --- \\
$(\mathrm{S})$ & --- & --- & 58,63 & 29,19 & 0,69 & 0,25 \\
$(\mathrm{Mn})$ & 1,20 & 0,69 & --- & --- & --- & --- \\
& 1,97 & 0,65 & --- & --- & --- & --- \\
& $100 \%$ & & $100 \%$ & & $100 \%$ &
\end{tabular}

Figura 8.

Imágenes TEM y EDS de nanopartículas obtenidas en el filtro CFM-2184 (ambiental).

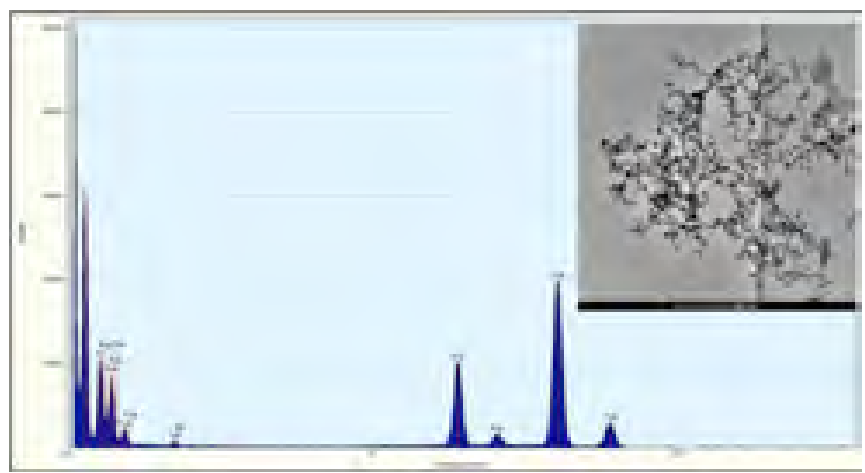

Figura 9.

Imágenes TEM y EDS de nanopartículas obtenidas en el filtro CFM-2184 (ambiental).

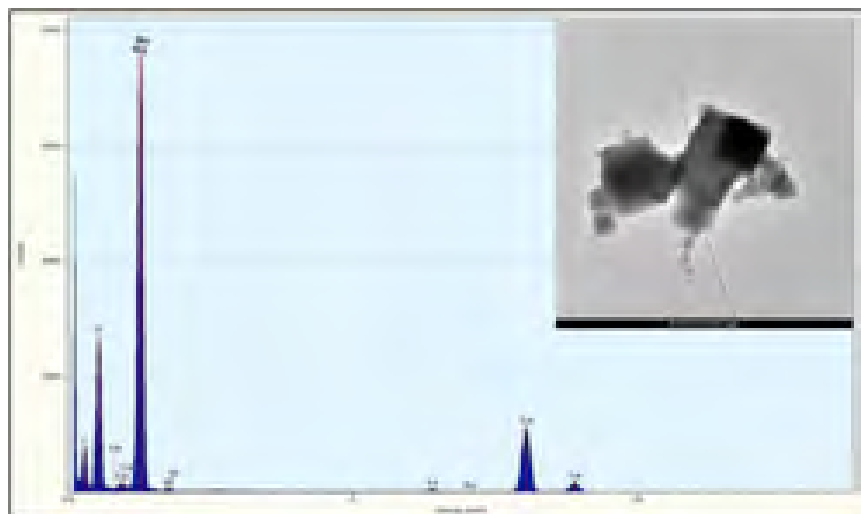

para aquellas que tienen tamaños nanométricas (menores de 100 nm), como se observa en las Figuras 7 y 8 . Además, hay presencia de partículas más grandes (del orden de los micrómetros) con morfología no granular, y nanopartículas de forma irregular y rectangular (Figura 9).

$\mathrm{Al}$ analizar las nanopartículas mediante EDS observamos la presencia de elementos tales como $0, \mathrm{Mg}, \mathrm{Si}, \mathrm{K}, \mathrm{Fe}, \mathrm{S}, \mathrm{y}$ Mn (Ver Tabla 3).

De las Figuras 7 y 8 se observa que la composición es similar a excepción del $\mathrm{Mg}$, el cual está presente en partículas de gran tamaño (del orden de micrómetros) en su mayor proporción en peso. En el filtro personal (CFM 2183), el Mg se encuentra en menor proporción en peso, en cambio en este filtro (CFM 2183) hay mayor concentración de silicio (Si). En el filtro CFM 2184 (ambiental) no hay presencia de $\mathrm{K}, \mathrm{Mn}, \mathrm{S}$ en las partículas estudiadas, pero no implica que en otro tipo de partículas no estén presentes.

También en el filtro ambiental (CFM 2184) encontramos formación de otro tipo de nanoestructuras no encontradas en el filtro personal (CFM 2183) con composición similar a las encontradas previamente (Figura 10).

La formación y composición de estas nanopartículas van a depender del proceso a la cual están siendo sometidos los elementos constituyentes (procesos de nucleación y crecimiento). Estas formas sugieren estructuras de carácter cristalino. 
Figura 10.

Imágenes TEM de nanoestructuras (nanoalambres) observadas en el filtro CFM-2184.

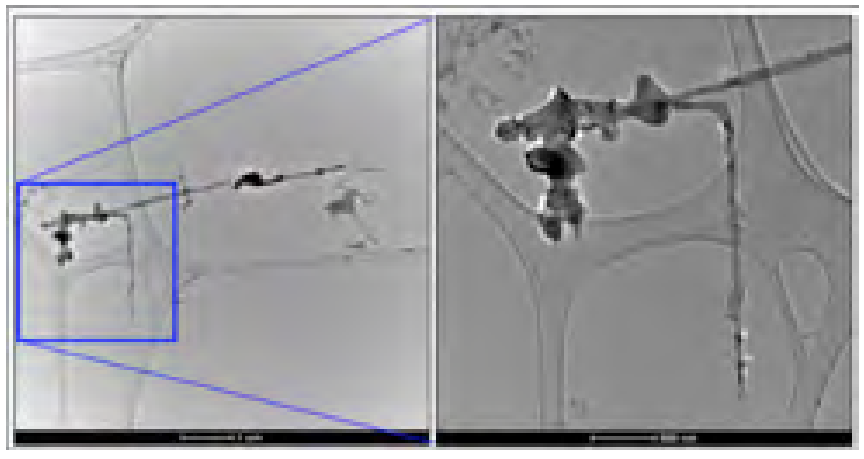

De estos resultados se concluye que:

- Se identificaron partículas nanométricas de interés higiénico como: $\mathrm{Si}, \mathrm{Fe}, \mathrm{Mg}$ y Mn y Aluminio, por tanto el trabajador se encuentra expuesto a estos agentes. Con los métodos de análisis empleados no es posible determinar el nivel de exposición a partículas nanométricas.

- La Sílice está en mayor porcentaje que otros elementos, y el patrón de difracción de electrones del área seleccionada muestra estructuras cristalinas, por lo cual se corrobora que las nanopartículas y partículas presentes son cristalinas. Además, en la imagen del filtro 1694 muestra claramente los planos de la red ("lattice fringes"), o huellas dactilares de los cristales.

- Se encontraron nanopartículas con una morfología esférica de tamaños < $100 \mathrm{~nm}$ en algunas de las muestras personales y ambientales se encontraron estructuras con una morfología irregular con formas de nanoalambres en la muestra ambiental con alto contenido de Magnesio. Este nanoalambre, por las características que presenta su crecimiento, posiblemente su estado es cristalino.

- La muestra ambiental se ubicó a la altura de la zona respiratoria, en el sector próximo de vaciado de material fundido a cubeta. Esto permite inferir que la exposición de los trabajadores a nanopartículas de distinta morfología posiblemente depende de gradientes de temperatura que influirian en la nucleación y crecimiento de estructuras y de la distancia al foco de generación.

\section{DISCUSIÓN}

De acuerdo a la bibliografía, la toxicidad de las partículas depende de factores físicos y químicos, al respecto:

\section{Factores Físicos:}

- La toxicidad aumenta con la disminución del tamaño por aumento del área superficial. En el vaciado de la colada desde el horno, el tamaño encontrado es inferior a $20 \mathrm{~nm}$.

- Estructuras de nanoalambres tienen mayor toxicidad que las esféricas. En fundición (vaciado de colada) se encontraron nanoalambres, los que podrían generar mayor toxicidad que las nanopartículas esféricas encontradas en procesos de soldadura MIG.

- Las estructuras cristalinas de las nanopartículas presentan mayor toxicidad que las amorfas. Se encontraron estructuras cristalinas en muestras de minería, fundición y soldadura; existiendo un elemento característico como la sílice. Se encontró sílice a tamaños de nanoescala y en forma cristalina en las muestras provenientes de la muestrera, molino, fundición; en el caso de la soldadura se encontraron partículas de tamaños pequeños y de características de estructuras cristalinas y amorfas. En el primer estudio en la soldadura sólo se indicó posible estructura amorfa.

- Menor toxicidad presentan las nanopartículas si forman aglomerados (en estos aplican fuerzas de Van der Walls, se dispersan por medios mecánicos) y aumenta la toxicidad si se encuentran como agregados (no se dispersan por medios mecánicos). En el presente estudio se encontraron aglomerados en las muestras de soldadura MIG.

\section{Factores Químicos:}

- La solubilidad es un factor químico; mayor es la toxicidad si el elemento es insoluble: por ejemplo, la sílice es insoluble y por tanto mayor posibilidad tiene de atravesar la barrera de los alvéolos, y en menor probabilidad las sustancias hidrosolubles (metales y compuestos metálicos). Como criterio preventivo, si se desconoce este parámetro a nivel de nanopartícula se asume como insoluble.

- En relación a la composición química a nivel de nanopartículas, el estado del arte menciona que si los compuestos padres son tóxicos, a nivel de nanoescala aumenta la toxicidad. A continuación se describe el principal efecto del compuesto padre a falta de información de la tóxico-cinética específica para cada compuesto a tamaño de nanoescala. Se mencionan las muestras con elementos mayoritarios en $\%$ peso ( $>10 \%$, excepto para el Manganeso), y el posible efecto sobre el organismo considerando la información del compuesto padre es en cada caso:

- Sílice (Si) en la muestrera (33,33\%, personal), en muestra de soldadura MIG (6;66\%, personal), en fundición (entre 16,7227,04\% personal, 33,28\% ambiental), estado cristalino. Calificada como cancerigena en el D.S. N 594 a nivel de micropartícula.

- Hierro (Fe) en las muestras de soldadura MIG (17,72-37,99\%, personal), en fundición (58,63\%, ambiental). El Hierro puede generar trastornos pulmonares hasta la enfermedad de la siderosis.

- Manganeso (Mn) se encontró en la muestra de la muestrera (8,75\%, personal). Este compuesto puede afectar el sistema nervioso central y respiratorio, y producir la neumonitis del Mn. En el D.S. $N^{\circ}$ 594, aparece como límite para humos de soldadura al arco.

- Níquel (Ni), se encontró sólo en la muestra ambiental del molino (49\%); puede producir asma hasta neumoconiosis. El D.S. 594 indica a este compuesto como posible cancerígeno; sólo existe evidencia a nivel de laboratorio.

Todas estas nanopartículas, por su tamaño y morfología, tienen su principal vía de ingreso a través de la inhalación, ingresando al tracto respiratorio y que por difusión o de la acción de macrófagos, tendrían la capacidad de alcanzar las neuronas y afectar el sistema nervioso central y el periférico. La distribución y el transporte, según la literatura, podría ocurrir a través del nervio olfativo y depositarse en el cerebro, distribuirse a través de la sangre 
al hígado, bazo, riñón, médula ósea. Aquellas nanopartículas con mayor solubilidad podrán ser eliminadas a través de la orina.

Según la bibliografía, un estudio científico evidenció exposición a altas concentraciones de polvo de pintura con contenido de sílice y nanosilicatos; concluye que la protección respiratoria es relevante para evitar el ingreso del tóxico. Por lo tanto, en los procesos evaluados, donde los trabajadores expuestos a nanopartículas de níquel, sílice, manganeso, entre otros, toma relevancia la elección y mantenimiento de la protección personal respiratoria al menos con medias máscaras con filtros de alta eficiencia P100, además de guantes para evitar el ingreso del tóxico por vía dérmica, los procedimientos de trabajo y los sistemas de extracción localizada.

Todos estos antecedentes y datos de caracterización levantados en este estudio conducen a avanzar en las líneas de investigación futuras para determinar los niveles de concentraciones, es decir, realizar estudios con mediciones cuantitativas de las nanopartículas en los ambientes laborales en la realidad nacional.

\section{En relación a los métodos de muestreo y análisis:}

Los análisis SEM/EDS y TEM/EDS permitieron caracterizar la composición elemental, morfología y tamaños de las submicropartículas y nanopartículas.

El filtro de PVC generó una señal de cloro al ser irradiado por el haz de electrones, interfiriendo $\mathrm{u}$ opacando los contaminantes colectados en el filtro de las muestras; esto se resolvió reemplazándolo con el filtro de éster de celulosa para muestreos posteriores.

En algunas muestras ocurrió que el filtro de éster de celulosa era afectado por la no conducción de los electrones; esto se resolvió con la inserción de una cinta de carbono conductor y grilla.

Los tiempos de muestreo en este estudio exploratorio se determinaron bajo el criterio de no saturación de la muestra para evitar interferencias en el análisis por microscopía electrónica SEM y TEM, y el tiempo que duró la operación.

A partir de la comparación entre el análisis composicional de nanopartículas (TEM) y del análisis de submicropartículas/micropartículas (SEM/FRX), se puede apreciar que no todas las composiciones están presentes a nivel de nanopartículas, como por ejemplo: el aluminio en la Muestrera, el níquel y sodio aparecen como nanopartícula y no a tamaño submicrónico en soldadura. Es decir, según el tipo de proceso se generan composiciones a escala submicrométrica o a escala nanométrica, lo cual se puede estudiar en futuros proyectos.

\section{CONCLUSIONES}

a) Se encontró la presencia de nanopartículas en los procesos y tareas de operaciones realizadas en empresas de sectores como el minero, fundición y soldadura y se concluye que existe exposición a estas.

b) La exploración realizada en los ambientes laborales permitió concluir que existe exposición laboral a nanopartículas de diferentes tamaños, morfología, composición y estructuras cristalinas en los procesos de: homogenizado y pulverizado de muestras, en soldadura MIG de estructuras de acero básico A-36, en fusión de metales y vaciado de colada en moldes.

c) En los procesos muestreados, el análisis composicional en \% peso reveló como agentes de interés higiénico, mayoritariamente ( $>10 \%$ peso) a nivel de nanopartículas: sílice, hierro, aluminio, calcio, cinc y sodio en muestras personales, y en las muestras ambientales se encontró sílice, hierro, níquel, cinc y sodio. La sílice y otros compuestos de aluminosilicatos que se encuentran en estado cristalino se presentaron en mayor \%, principalmente en muestras personales de procesos mineros y de fundición y el hierro en procesos de soldadura.

d) En este estudio se identificaron estructuras esféricas, irregulares en forma de aglomerados, rectangulares, nanoalambres, y nanobarras. Todas estas clasificaciones descritas en la bibliografía y que le dan distinta toxicidad a las nanopartículas.

e) En el primer estudio de nanopartículas financiado por Fucyt se identificó la presencia de sílice amorfa en una muestra proveniente de un proceso de soldadura al arco con uso de varillas con recubrimiento para soldar, sin ser concluyente. En este segundo estudio de carácter exploratorio, en las muestras de soldadura al arco MIG que emplea electrodo continuo se corrobora el hallazgo del primer estudio, pero además de la amorfa se identifican estructuras cristalinas con contenido de sílice y fierro.

f) Líneas a desarrollar en el futuro deben estar en el marco cuantitativo para determinar concentraciones de nanopartículas y niveles de exposición en cuanto a número y distribución, por lo cual se van a requerir equipos muestreadores selectivos con recuento de tamaño de partículas del orden de los nanómetros. Lo cual toma relevancia si se establecen límites permisibles nacionales para partículas de tamaño nano.

g) Limitaciones del Estudio: Dado que no existe equipamiento para muestrear nanopartículas a nivel nacional, por costos de equipamiento y que están fuera del alcance de este proyecto exploratorio, no es posible determinar niveles de exposición o concentraciones de número de partículas en los ambientes estudiados, solo determinar que existe exposición y la caracterización de estas. 


\section{REFERENCIAS}

1. Oberdörster G. Pulmonary effects of ultrafine particles. Int Arch Occup Environ Health. 2001;74:1-8.

2. Donaldson $K$, Brown D, Clouter A. The pulmonary toxicology of ultrafine particles. J Aerosol Med. 2002;15:213-220.

3. Pietroiusti A. Health implications of engineered nanoparticles. Nanoscale. 2012;4:1231-1247.

4. Gutiérrez L, Hernández MJ, Molina L. Daños para la salud tras exposición laboral a nanopartículas. Med Segur Trab. 2013; 59(231):276-296.

5. Instituto Riojana de Salud Laboral. La seguridad y salud en la exposición a nanopartículas [en línea]. La Rioja: IRSAL; 2011 [consultado mar 2015]. Disponible en: https://www.larioja.org/npRioja/cache/documents/557016_ NANOPARTICULAS.pdf

6. Gálvez V, Tanarro C. Toxicología de las nanopartículas [poster]. Simposium de Higiene Industrial, 26-27 nov 2009; Murcia, España. Madrid: Centro Nacional de Nuevas Tecnologías; 2010 [consultado mar 2015]. Disponible en: http:// www.insht.es/InshtWeb/Contenidos/Documentacion/TextosOnline/postersTecnicos/ficheros/Toxicolog\%C3\%ADa\%20de\%20las\%20nanopart\%C3\%ADculas. pdf.

7. Zúñiga R, Blamey $X$, Ahumada L, Mosquera E. Estudio Exploratorio de Higiene Industrial y seguridad básica en unidades de trabajo que generan o manipulan nanopartículas, o que emplean nanotecnología en sus procesos. Proyecto Fucyt P0068 2011-2012. Santiago: ACHS; s.a.

\section{Referencias Consultadas}

British Standards Institute (BSI). Nanotechnologies, Part 1: Good Practice Guide for Specifying Manufactured Nanomaterials. London: British Standards Institute; 2007. (PD 6699-1)

Cheng TH, Ko FC, Chang JL, Wu KA. Bronchiolitis obliterans organizing pneumonia due to titanium nanoparticles in paint. Ann Thor Surg. 2012;93:666-669.

Silverman DT et al. The Diesel Exhaust in Miners Study: A Nested Case Control Study of Lung Cancer and Diesel Exhaust J Natl Cancer Inst. 2012;104(11):855-868.

Hartmann $L$ et al. Assessment of the biological effects of welding fumes emitted from metal inert gas welding processes of aluminium and zinc-plated materials in humans. Int J Hyg Environ Health. 2014;217(2-3):160-168.

Japan National Institute of Advanced Industrial Science and Technology (AIST). Final Reports on Risk Assessments of Three Manufactured Nanomaterials [on line]. Tokio: AIST; 2011 [consultado mar 2015].Disponible en: http://www.aistriss.jp/ main/modules/product/nano_rad.html.

Kuhlbusch TA et al. Nanoparticle exposure at nanotechnology workplaces: a review. Part Fibre Toxicol. 2011;8:22.

Liu CN et al. Exposure assessment of nano-sized and respirable particles at different workplaces. J Nanopart Res. 2011;13:4161-4172.

The National Institute for Occupational Safety and Health (NIOSH). Approach to safe Nanotechnology. Atlanta: CDC-NIOSH; 2009. (DHHS-NIOSH Publication, No. 2009-125).

Ostiguy C, Roberge B, Woods C, Soucy B. Les Nanoparticules de Synthèse: Connaissances actuelles sur les risques et les mesures de prévention en SST. $2^{\text {a }}$ ed [on line]. Montreal: IRSST ; 2010. (Etudes et Recherches, Rapport R-646) [consultado mar 2015]. Disponible en: http://www.irsst.qc.ca/media/documents/PubIRSST/R-646.pdf

Phillips J, Green FY, Davies JC, Murray J. Pulmonary and systemic toxicity following exposure to nickel nanoparticles. Am J Ind Med. 2010;53:763-767.

Ramachandran $G$ et al. A Strategy for Assessing Workplace Exposures to Nanomaterials. J Ocupp Environ Hyg. 2011.8:673-685.

Roco MC. The long view of nanotechnology development: the National Nanotechnology Initiative at 10 years. J Nanopart Res. 2011;13:427-445

Song Y, Li X, Du X. Exposure to nanoparticles is related to pleural effusion, pulmonary fibrosis and granuloma. Eur Respir J. 2009;34:559-567.

Song Y, Li X, Wang L et al. Nanomaterials in humans: identification, characteristics, and potential damage. Toxicol Pathol. 2011;39:841-849.

Van Broekhuizen $\mathrm{P}$, van Veelen W, Streekstra W-H, Schulte P, Reijnders L. Exposure limits for nanoparticles: report of an international workshop on nano reference values. Ann Occup Hyg. 2012;56:515-524.

Warheit DB, Webb TR, Reed KL, Frerichs S, Sayes CM. Pulmonary toxicity study in rats with three forms of ultrafine-TiO2 particles: differential responses related to surface properties. Toxicology. 2007;230(1):90-104. 